\title{
Addition of bevacizumab to systemic therapy for locally advanced and metastatic nasopharyngeal carcinoma
}

\author{
HUI-JIE ZHANG, GAO-LE YUAN, QI-LIAN LIANG, XIAO-XIA PENG, SHAO-ANG CHENG and LIANG JIANG
}

Oncology Center, Affiliated Hospital of Guangdong Medical University, Zhanjiang, Guangdong 524001, P.R. China

Received July 22, 2017; Accepted February 5, 2018

DOI: $10.3892 / \mathrm{ol} .2018 .8284$

\begin{abstract}
Radiotherapy is a vital treatment option for patients with nasopharyngeal carcinoma (NPC). Concurrent cisplatin-based radiochemotherapy with or without adjuvant chemotherapy had acquired good clinical effects with good local control rates. However, a number of patients present with metastasis following systemic regimens or initial diagnosis of locally advanced NPC, which cause difficulty for subsequent therapy. Therefore, there is an urgent requirement to discover novel targeted therapies. The present report describes one case of a patient with NPC and multiple metastases. The patient was treated with systemic therapy in combination with bevacizumab, palliative radiotherapy and chemotherapy following treatment with cetuximab and concurrent chemoradiotherapy in 2015. Following the addition of bevacizumab, metastases were reduced or disappeared after $>2$ months, and the duration of progression-free survival was 7 months. Bevacizumab is a monoclonal antibody that targets VEGF, and it is associated with angiogenesis, which causes the growth, invasion and progression of tumors. In previous studies, bevacizumab has been approved for the treatment of several types of malignant cancer and it has been able to effectively improve prognosis. In the present review, the effect of adding bevacizumab to systemic therapy for the treatment of NPC was analyzed, with a particular focus on advanced and metastatic diseases. A growing number of phase I/II clinical trials involving bevacizumab for NPC
\end{abstract}

Correspondence to: Professor Qi-Lian Liang, Oncology Center, Affiliated Hospital of Guangdong Medical University, 57 People Avenue, Zhanjiang, Guangdong 524001, P.R. China

E-mail: lianqilian@gdmu.edu.cn

Abbreviations: NPC, nasopharyngeal carcinoma; VEGF, vascular endothelial growth factor; OS, overall survival; PFS, progression-free survival; RT, radiotherapy; HIF-1, hypoxia-inducible factor 1; HIF- $1 \alpha$, hypoxia-inducible factor- $1 \alpha$; HIF- $1 \beta$, hypoxia-inducible factor-1 $\beta$; EGFR, epidermal growth factor receptor; CR, complete responses; PR, partial responses; PET-CT, positron emission tomography-computed tomography; HNSCC, head and neck squamous cell carcinoma; IMRT, intensity-modulated radiation therapy; FDA, US food and drug administration

Key words: NPC, nasopharyngeal carcinoma, VEGF, vascular endothelial growth factor, HIF-1, hypoxia-inducible factor 1 have been conducted with clinical outcomes showing improved rates of overall survival and progression-free survival as well as improvements in the quality of life of patients. However, severe or deadly toxicities can also result from combination treatment with bevacizumab. In the future, bevacizumab may become a common addition to systemic therapy for the treatment of locally advanced and metastatic NPC.

\section{Introduction}

NPC is endemic in Southern China, particularly in Guangdong and Guangxi (1). NPC originates from the epithelial lining of the nasopharynx, and it is classified into three histological types according to the World Health Organization (2-4). Type I NPC refers to keratinizing squamous cell carcinoma. Type II is non-keratinizing squamous cell carcinoma, and type III is undifferentiated squamous cell carcinoma (2-4). In general, types II and III are regarded together as undifferentiated carcinomas, where the incidence of metastasis is higher compared with type I NPC $(3,5)$. In Guangdong province, the most common type of NPC is undifferentiated carcinoma, which is sensitive to radiation but is more prone to developing into distant metastasis compared with type I NPC $(2,3,5)$. The undifferentiated type usually results in poor prognosis (6).

With the sensitivity of such disease to radiation, radiotherapy (RT) remains the mainstay treatment for patients with NPC $(7,8)$. However, the majority of patients with NPC are initially diagnosed at late stages of the disease on the account of its complex anatomical location (1). These patients often miss the optimum treatment time because of therapy failure despite the development of RT methods, chemotherapy regimen, and targeted drugs, which results in relapse or distant metastasis (9). As reported, the 5-year local control rate of NPC ranges from 80 to 85 , and $\sim 30 \%$ of patients with NPC exhibit local recurrence and distant metastasis, which hinder successful treatment $(10,11)$. In patients with metastasis, the 5-year overall survival (OS) rate ranges from 28 to $61 \%$, and median OS (mOS) rate lasts $\geq 1-12$ months (12). The cohort of patients with metastatic NPC presents poorer prognosis compared with those with non-metastatic diseases with OS of 7-10 months (13).

The National Comprehensive Cancer Network guideline (version 1.2017) (14) recommends concurrent chemotherapy (with cisplatin preferably) and RT for locally advanced NPC and combined therapy for metastatic NPC (category 1 evidence). Systemic therapy for patients with locally advanced 
NPC (stages III-IVb; American Joint Committee on Cancer manual; seventh edition) (15) is a concurrent chemoradiotherapy with or without cisplatin-based adjuvant chemotherapy with proven improved OS rates compared to patients treated with non-systemic therapies $(7,8,16,17)$. Palliative chemotherapy remains the main strategy for patients with metastatic NPC (9). The addition of targeted therapy as a first-line treatment (or beyond) of locally advanced and metastatic NPC has a marked effects on outcomes, including progression-free survival (PFS) and OS rates (9). Along with RT and chemotherapy, treatment strategies involving anti-angiogenic therapy have been considered feasible in recent years $(13,17)$.

\section{Case report}

The present authors treated a 21-year-old male with multiple metastatic undifferentiated non-keratinizing NPC (lymph nodes, bone, lung and pleura) based on nasopharyngeal biopsy pathology and positron emission tomography-computed tomography (PET-CT) with systemic therapy in combination with bevacizumab ( $7.5 \mathrm{mg} / \mathrm{kg}$ intravenously every 3 weeks), palliative RT of 30 Gy to the lumbosacral region and chemotherapy following treatment with cetuximab (initially at $400 \mathrm{mg} / \mathrm{sqm}$, then $250 \mathrm{mg} / \mathrm{sqm}$ i.v., every 3 weeks, total 3 times) and concurrent chemoradiotherapy in the Affiliated Hospital of Guangdong Medical University (Zhanjiang, China) on May 21, 2015. The patient had a history of chronic hepatitis B for 3 years without any prior therapies, and a history of smoking and alcohol intake for 10 years. There were no similar cases in his family. Following the addition of bevacizumab, this patient experienced relief when metastasis was reduced or disappeared according to positron emission tomography-computed tomography (PET-CT) after $>2$ months (Figs. 1-6). The duration of PFS was 7 months, and the patient succumbed to disease in January 2016 as continuous treatment was refused due to economic factors. Nevertheless, the present case still provided strong evidence for the ability of bevacizumab to relieve cisplatin-induced resistance in combination therapy.

The rapid growth of tumors causes a lack of oxygen. Hypoxia-inducible factor (HIF)-1 is a transcription factor, and there are multiple isoforms, including HIF-1 $\alpha$ and HIF-1 $\beta$. HIF-1 is activated to regulate hypoxia-adaptive responses and activates downstream vascular endothelial growth factor (VEGF) genes, which play pivotal roles in a series of tumor-associated biological activities (Fig. 7) (1,18-23).

VEGF was initially discovered as atumor-secreted protein (24) and can be detected in serum and tumor specimens (25). VEGF is located at chromosome $6 \mathrm{p} 12$, and it comprises a coding region with eight exons and seven introns (1). The VEGF gene family includes VEGF-A, -B, -C, -D and -E (13,26-28). Among these factors, VEGF-A is considered the most important in regulating tumor angiogenesis. There are three types of VEGF receptor (VEGFR) found on the cell surface: VEGFR-1, -2, and -3 (13). In particular, VEGF-A binds with VEGFR-1 and VEGFR-2, which leads to signal transduction $(28,29)$. VEGF-C and -D regulate lymphatic vessel endothelium and promote lymphangiogenesis and invasion of tumor cells in patients with NPC via binding with VEGFR-3 (30).

VEGF is a tumor-induced factor that contributes to angiogenesis, tumorigenesis and metastasis (1,24,25,31-35). VEGF

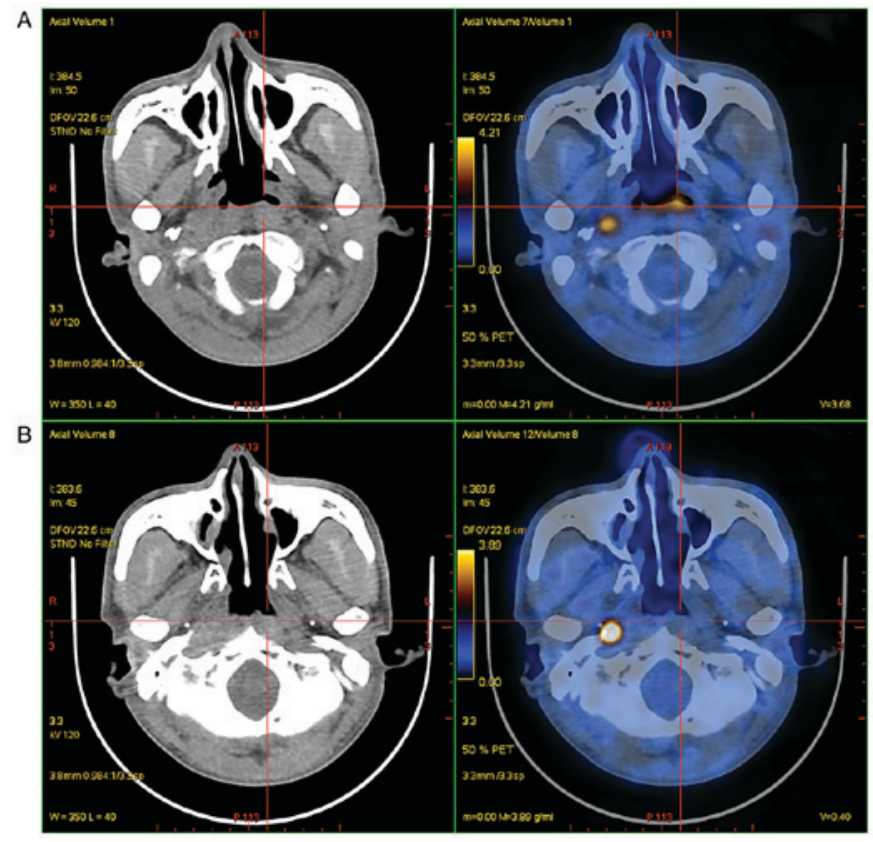

Figure $1 .{ }^{18} \mathrm{~F}-\mathrm{FDG}$ PET-CT scans of the whole body of the patient showing reduction in the site of an enlarged lymph node. (A) The PET-CT scan was taken in August 2015. A reduction in the enlarged lymph node (size, $1.0 \times 1.1 \mathrm{~cm}$ ) in the right posterior oropharynx with lower hypermetabolism is indicated compared with the scan taken in May 2015. SUVmax, 3.9. (B) The PET-CT scan was taken in May 2015. An enlarged lymph node (size, $1.0 \times 1.3 \mathrm{~cm}$ ) was detected in the right posterior oropharynx with hypermetabolism. SUVmax, 6.8. PET-CT, positron emission tomography-computed tomography; SUVmax, maximum standardized uptake value.

expression is associated with poor prognosis in patients with NPC (36). VEGF is expressed in head and neck cancer cells and in $67 \%$ of tumors from NPC biopsy specimens $(11,12,31,37,38)$. The association between VEGF and angiogenesis has been reported in breast cancer, colorectal cancer and head and neck squamous cell carcinoma (HNSCC) (7,24). In one study, patients with decreased VEGF expression $(77.8 \%)$ became disease-free, whereas patients with increased VEGF expression $(66.7 \%)$ exhibited persistent or early relapse (25). The overexpression of VEGF increases the resistance of tumor cells to chemotherapy or RT and regulates the tumor microenvironment $(1,2)$. One study has regarded high levels of VEGF expression to present difficulties for anti-epidermal growth factor receptor (EGFR) therapy (39). A potential mechanism for resistance is that VEGF protects endothelial cells from radiation and cytotoxic drugs and increases resistance of tumors to RT, chemotherapy and anti-EGFR therapy (40-42).

The concept of blocking angiogenesis, which may be a potential strategy for cancer treatment, was initially raised in 1971 (32). A growing number of studies on angiogenesis inhibitors in NPC were conducted since the concept was first raised (43). VEGF inhibitors decrease the density of blood vessels in tumors, which decrease the ability of tumors to meet its metabolic needs for growth and progression $(26,28,44)$. This observation is the foremost mechanism of anti-VEGF therapy.

Vascular normalization window, when the function, structure and microenvironment of tumor blood vessels become normalized temporarily so that anticancer drugs can easily infiltrate into tumor tissue, is a typical factor for cancer radiosensitivity, implying that systemic therapy comprising anti-angiogenic 

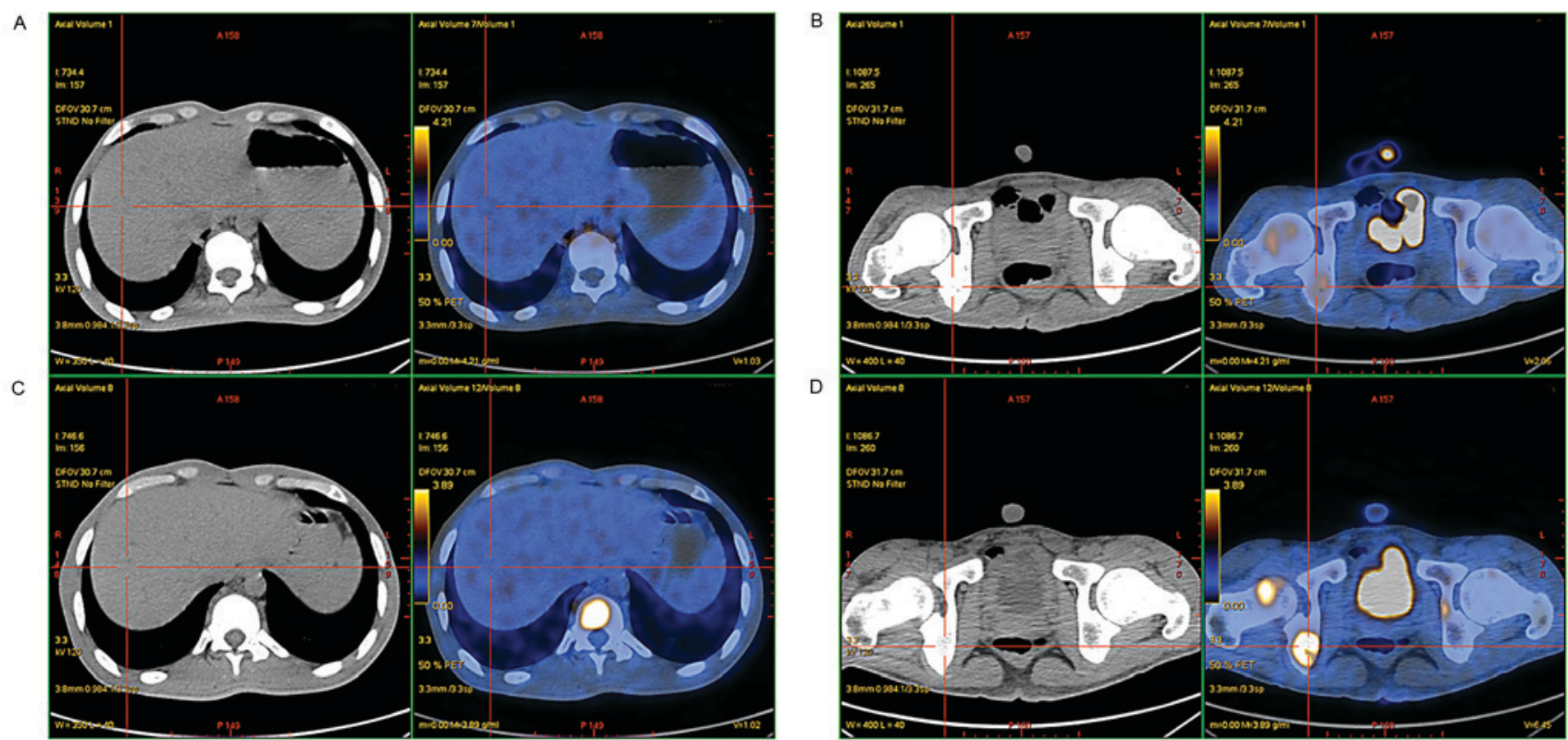

Figure $2 .{ }^{18}$ F-FDG PET-CT scans of the whole body of the patient showing reducing in lymph node metastasis. (A) The PET-CT scans were taken in August 2015 A marked reduction in lymph node metastasis was detected in right neck with lower hypermetabolism compared with the scan taken in May 2015. SUVmax, 4.0. (B) The PET-CT scans were taken in August 2015. A marked reduction in lymph node metastasis was detected in left neck with lower hypermetabolism compared with the scan taken in May 2015. SUVmax, 4.0. (C) The PET-CT scans were taken in May 2015. Multiple metastatic lymph nodes were detected in right neck with hypermetabolism. SUVmax, 8.0. (D) The PET-CT scans were taken in May 2015. Multiple metastatic lymph nodes were detected in left neck with hypermetabolism. SUVmax, 8.0. PET-CT, positron emission tomography-computed tomography; SUVmax, maximum standardized uptake value.

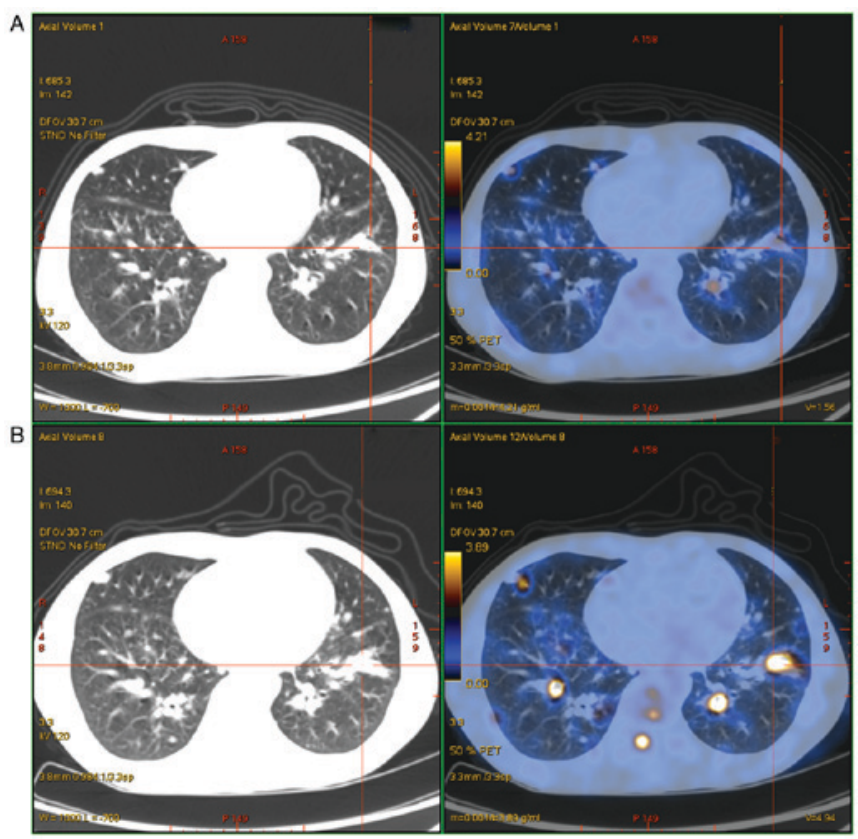

Figure 3. ${ }^{18}$ F-FDG PET-CT scans of the whole body of the patient showing reduction of multiple nodular shadows in the left lung. (A) The PET-CT scan was taken in August 2015. Reduction of multiple nodular shadows of different sizes (maximum size, $0.5 \times 0.8 \mathrm{~cm}$ ) in the left lung with lower hypermetabolism was detected. SUVmax, 1.6. (B) The PET-CT scan was taken in May 2015. Multiple nodular shadows of different sizes (maximum size, $1.4 \times 1.6 \mathrm{~cm}$ ) with hypermetabolism were detected in the left lung. SUVmax, 5.6. PET-CT, positron emission tomography-computed tomography; SUVmax, maximum standardized uptake value.

therapy and radiation is not just a simple combination of the two therapies (26). Anti-angiogenic therapy increases radiation response in xenograft human models of NPC (1).
Bevacizumab (Avastin) is a recombinant humanized IgG1 monoclonal antibody that targets VEGF (Fig. 8) $(31,32,45)$. In previous studies, bevacizumab has been demonstrated to have a definite clinical effect on inhibiting metastatic colorectal cancer, non-small-cell lung cancer, kidney cancer, gynecologic tumors and breast cancer $(31,46)$. Bevacizumab therapy has contributed significantly to the outcomes of patients with malignant cancer, particularly those with systemic metastasis. To date, only cetuximab, an EGFR antibody, has been demonstrated to be effective for the treatment of locally advanced and metastatic NPC (42). However, the incidence of local recurrence and distant metastatic NPC remain at extremely high levels $(41,43)$. Therefore, the development of novel targeted therapies is urgently required. Several studies have highlighted the anti-tumor effects of bevacizumab on HNSCC tumor xenografts in mice $(6,44,45,47)$. Bevacizumab has no direct anti-tumor effect on NPC CNE1 cells in vitro, and this is potentially due to the lack of vascular endothelial cell receptors $(12,18)$. Treatment with a combination of bevacizumab and paclitaxel exerts greater inhibitory effects compared with employing either agent alone. The use of the combination of bevacizumab and paclitaxel is able to prevent the formation of new blood vessels and trigger apoptosis in cultured tumor cells (31). Additionally, the use of anti-VEGF may increase the anti-tumor effect of RT and chemotherapy drugs potentially via the vascular normalization mechanism and the augmentation of endothelial cell injury $(6,31,47)$. He et al (12) published a case in 2016 on a patient with stage IV NPC who was treated with a regimen of bevacizumab, paclitaxel, liposome and cisplatin. This patient achieved a stabilized condition 2 months following the addition of bevacizumab. The duration of PFS of the patient reached 7 months. Li et al (48) proposed that the combination of bevacizumab, cisplatin and TomoTherapy (TOMO) can result in good clinical effects, with $80 \%$ complete response and $40 \%$ 


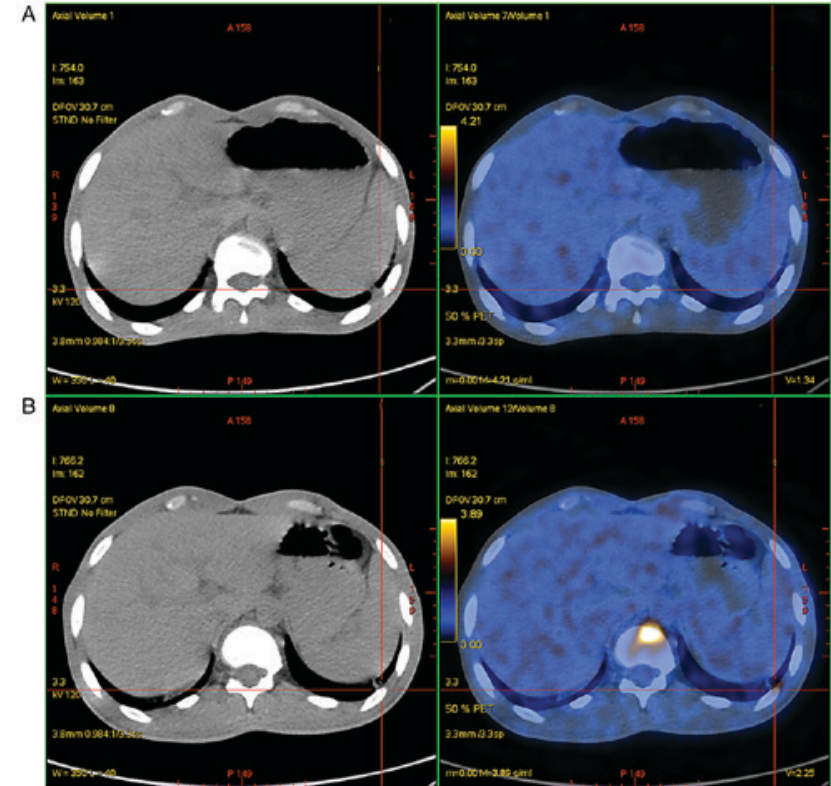

Figure $4 .{ }^{18} \mathrm{~F}$-FDG PET-CT scans of the whole body of the patient showing reduction of multiple nodular shadows in the left pleura. (A) The PET-CT scan was taken in August 2015. Reduction of multiple nodular shadows in the left pleura with lower hypermetabolism was detected. (B) The PET-CT scan was taken in May 2015. Multiple nodular shadows of different sizes with hypermetabolism were detected in the left pleura. PET-CT, positron emission tomography-computed tomography; SUVmax, maximum standardized uptake value.

partial response with low toxicity. The study by Li et al (48) was followed-up with 30 patients with stage III-IV NPC. The patients received a systemic therapy involving a combination of bevacizumab $(5 \mathrm{mg} / \mathrm{kg})$, cisplatin $\left(80 \mathrm{~kg} / \mathrm{m}^{2}\right)$ and RT $(67.5 \mathrm{~Gy}$; helical TOMO) (48). This study provides basis for in-depth research on the use of anti-VEGF treatment and further verifies the curative effect of the addition of bevacizumab to therapy.

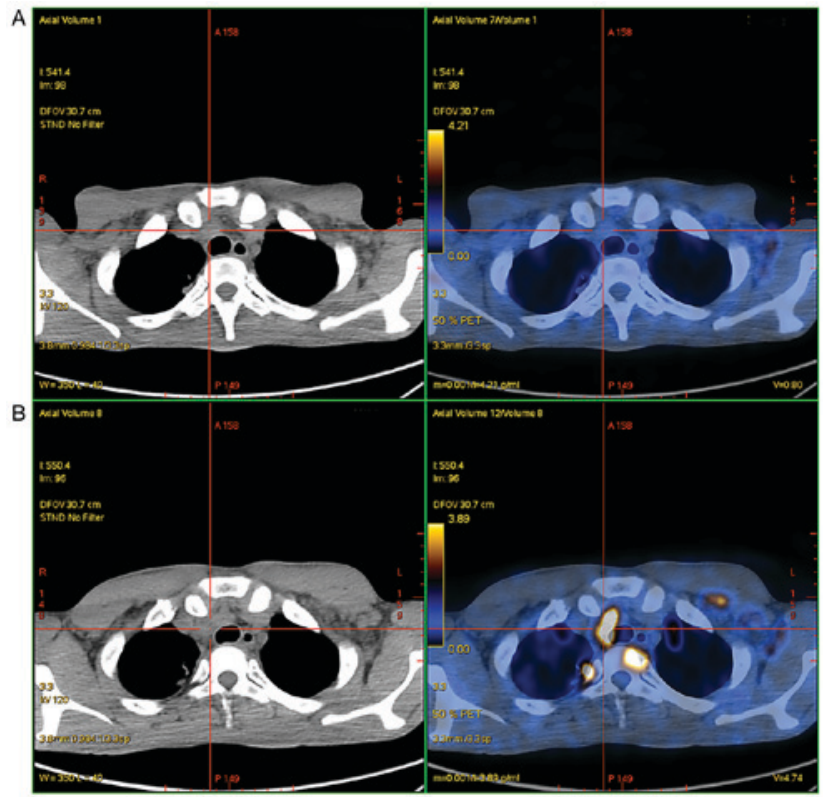

Figure 5. ${ }^{18} \mathrm{~F}$-FDG PET-CT scans of the whole body of the patient showing the disappearance of multiple enlarged lymph nodes in the mediastinum. (A) The PET-CT scan was taken in August 2015. The disappearance of multiple enlarged lymph nodes in the mediastinum with lower hypermetabolism was detected. SUVmax, 3.7. (B) The PET-CT scan was taken in May 2015. Multiple enlarged lymph nodes (maximum size, $2.9 \times 4.3 \mathrm{~cm}$ ) in the mediastinum with hypermetabolism were detected. SUVmax, 8.4. PET-CT, positron emission tomography-computed tomography; SUVmax, maximum standardized uptake value.

With regards to locally advanced and metastatic NPC, many clinical trials were carried out to test the efficacy and safety of bevacizumab. These trials offer theory of proof for clinicians (Table I). A phase II multi-institutional trial (RTOG 0615) showed that addition of bevacizumab to systemic chemoradiotherapy for patients with stage IIB-IVB NPC is feasible and may
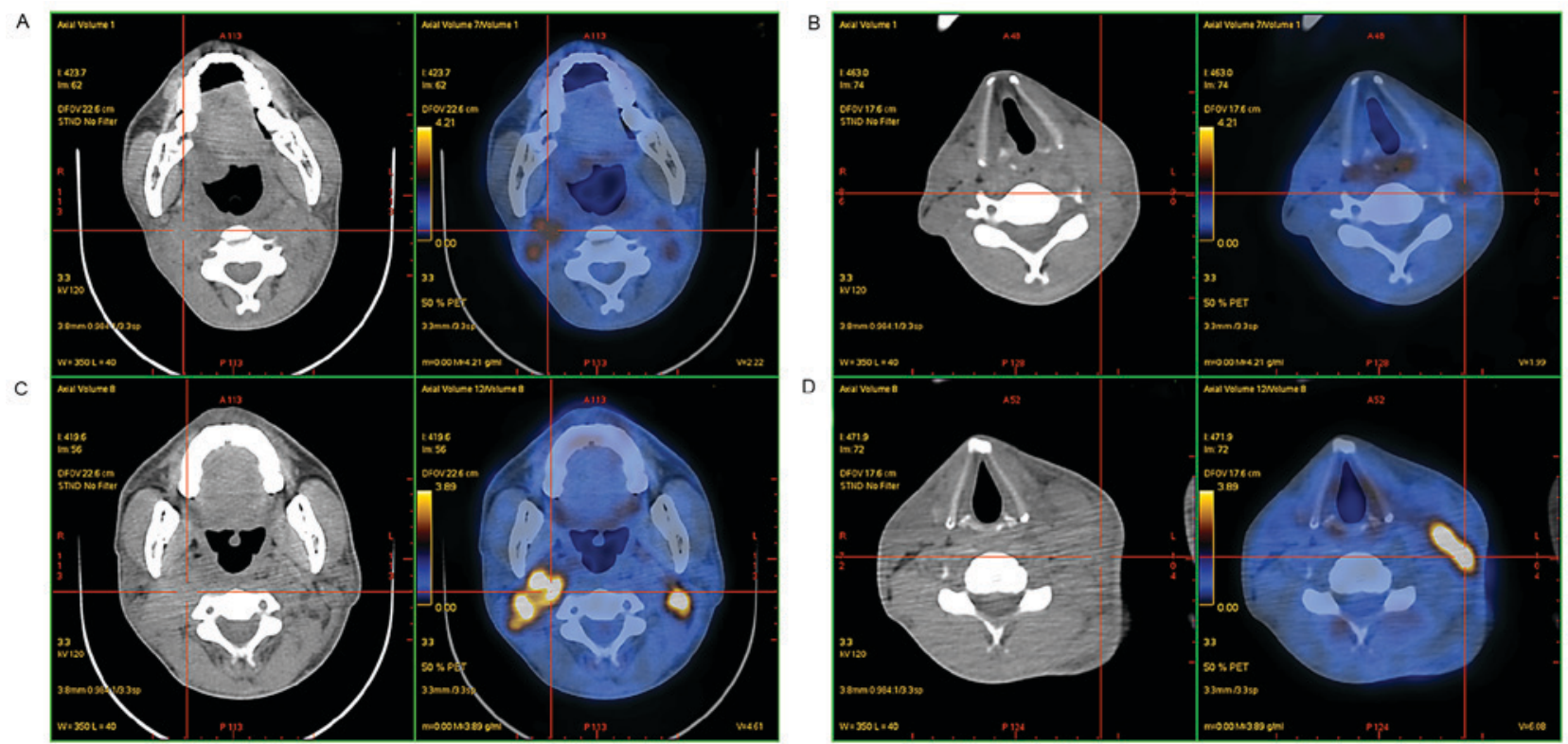

Figure $6 .{ }^{18}$ F-FDG PET-CT scans of the whole body of the patient showing reduction of multiple bones metastases in the thoracic vertebrae and the right ischium. The PET-CT scans were taken in August 2015. A reduction in multiple bone metastases in the (A) thoracic vertebrae and the (B) right ischium was detected. The PET-CT scans were taken in May 2015. Multiple bone metastases in the (C) thoracic vertebrae and the (D) right ischium were detected. PET-CT, positron emission tomography-computed tomography; SUVmax, maximum standardized uptake value. 
Table I. Details of clinical trials with combination therapy involving bevacizumab.

\begin{tabular}{|c|c|c|c|c|c|c|c|}
\hline $\begin{array}{l}\text { Treatment type } \\
\text { (in addition to } \\
\text { bevacizumab) }\end{array}$ & Disease setting & Phase & Year & Target & $\begin{array}{l}\text { Mechanism } \\
\text { of action }\end{array}$ & Results & (Refs.) \\
\hline Erlotinib & $\begin{array}{l}\text { Recurrent/metastatic } \\
\text { (first or second-line) }\end{array}$ & $\mathrm{I} / \mathrm{II}$ & 2009 & $\begin{array}{l}\text { Anti-EGFR } \\
\text { and anti-VEGF }\end{array}$ & Cytotoxic & $\begin{array}{l}\mathrm{RR}, 15 \% ; \mathrm{mPFS}, \\
4.1 \text { months; mOS, } \\
7.1 \text { months }\end{array}$ & (39) \\
\hline $\begin{array}{l}\text { Chemotherapy } \\
\text { and RT }\end{array}$ & $\begin{array}{l}\text { Newly diagnosed locally } \\
\text { advanced cancer with } \\
\text { poor-prognosis }\end{array}$ & I & 2008 & Anti-VEGF & $\begin{array}{l}\text { Cytotoxic } \\
\text { and radiation }\end{array}$ & mOS, 10.7 months & $(51)$ \\
\hline $\begin{array}{l}\text { Erlotinib and } \\
\text { concurrent } \\
\text { chemotherapy/RT }\end{array}$ & $\begin{array}{l}\text { Locally advanced } \\
\text { (first-line) }\end{array}$ & II & 2009 & $\begin{array}{l}\text { Anti-EGFR } \\
\text { and anti-VEGF }\end{array}$ & $\begin{array}{l}\text { Cytotoxic and } \\
\text { radiation }\end{array}$ & $\begin{array}{l}\text { ORR, } 77 \% \text {. } \\
\text { 18-months PFS } 85 \% \text {, } \\
\text { 18-months OS, } 87 \%\end{array}$ & $(52)$ \\
\hline $\begin{array}{l}\text { Cisplatin and } \\
\text { IMRT }\end{array}$ & $\begin{array}{l}\text { Locally advanced } \\
\text { (first-line) }\end{array}$ & II & 2009 & Anti-VEGF & $\begin{array}{l}\text { Cytotoxic and } \\
\text { radiation }\end{array}$ & $\begin{array}{l}\text { Locoregional control } \\
\text { rate, 100\%; estimated } \\
\text { 1-year PFS 83\%; } \\
\text { estimated 1-year } \\
\text { OS, } 88 \%\end{array}$ & (53) \\
\hline $\begin{array}{l}\text { Cisplatin and } \\
\text { IMRT }\end{array}$ & $\begin{array}{l}\text { Locally advanced } \\
\text { (first-line) }\end{array}$ & II & 2012 & Anti-VEGF & $\begin{array}{l}\text { Cytotoxic and } \\
\text { radiation }\end{array}$ & $\begin{array}{l}\text { 2-year PFS, } 75.9 \% \text {; } \\
\text { 2-year OS, } 88 \%\end{array}$ & $(50)$ \\
\hline
\end{tabular}

EGFR, epidermal growth factor receptor; RR, response rate; IMRT, intensity-modulated relation therapy; mPFS, median progression-free survival; mOS, median overall survival; ORR, overall response rate; RT, radiotherapy; VEGF, vascular endothelial growth factor.

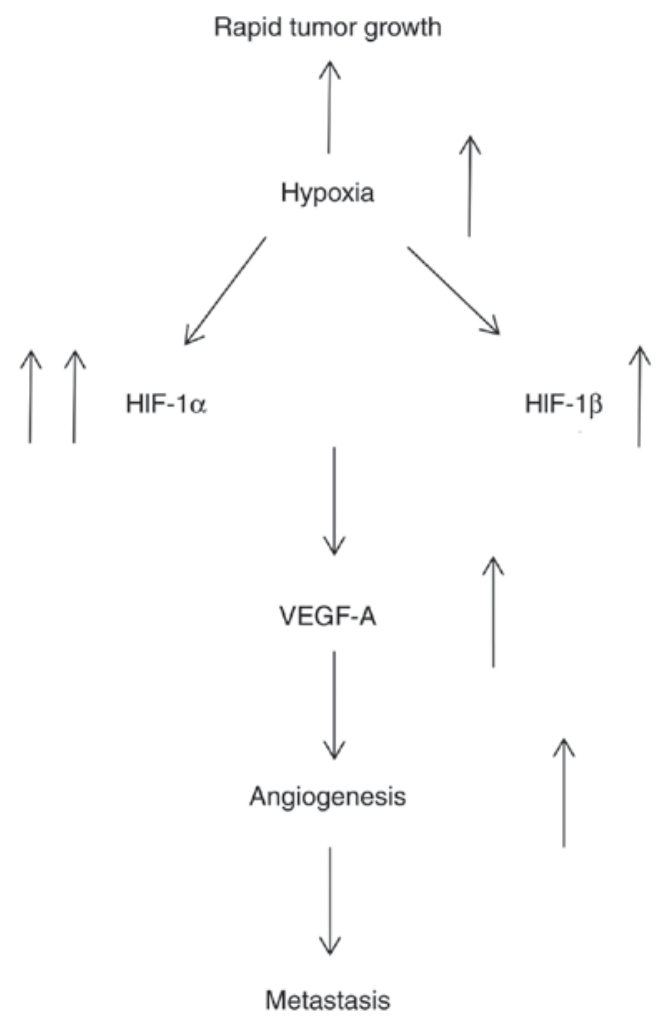

Figure 7. Schematic diagram of the development of nasopharyngeal carcinoma metastasis via VEGF. HIF, hypoxia-inducible factor; VEGF, vascular endothelial growth factor.

function in blocking invasion of tumor cells (49). The combination of bevacizumab and erlotinib improves efficacy with an observed response rate of $15 \%$, whereas severe or late side

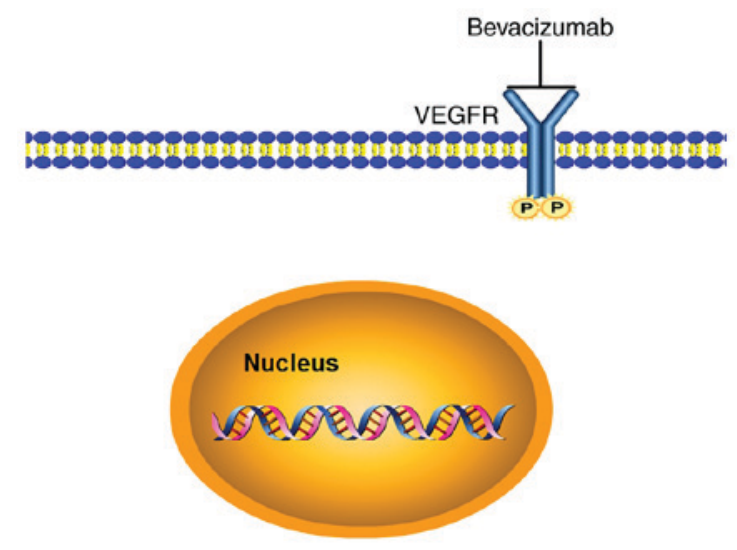

Figure 8 . Signaling pathway that is deregulated by bevacizumab in nasopharyngeal carcinoma. VEGFR, vascular endothelial growth factor receptor.

effects have not been observed in another phase II trial (39). A phase I research on bevacizumab, fluorouracil, hydroxyurea and radiation in patients with recurrent NPC, achieved promising mOS rate of 10.7 months (50). Pfister et al (51) treated patients with locally advanced HNSCC using protocol of bevacizumab and cisplatin and intensity-modulated radiation therapy (IMRT), which yielded $100 \%$ locoregional control rate, $83 \%$ 1-year PFS rate, and 88\% 1-year OS rate in 2009. Similarly, in 2012, Fury et al (52) also conducted a phase II study on patients with stage III-IV HNSCC and treated them with the same treatment as those of Pfister et al (51); this study yielded 75.9\% 2-year PFS rate and 88\% 2-year OS rate. Meluch et al (53) conducted a trial on patients with locally advanced HNSCC and treated with bevacizumab, erlotinib, chemotherapy, and RT; their study obtained an objective response rate of 77\%, 18-month PFS rate 
of $85 \%$, and 18 -month OS rate of $87 \%$ (53). Some phase III trials have surveyed recurrent or metastatic HNSCC (E1305) (54). Phase I/II studies are common, whereas phase III studies are rarely conducted. More tests are urgently needed to confirm feasibility of combination of bevacizumab and chemotherapy or RT. Addition of bevacizumab to RT may be a promising strategy and may restrain poor preclinical outcomes.

The usual side effects of bevacizumab include hypertension, bleeding, gastrointestinal perforation, cardiotoxicity, and thromboembolic events $(32,55)$. In the past, patients treated with anti-angiogenetic drugs surrendered early due to severe and lethal side effects. However, with the development of drugs and clinical management, common side effects are now easily managed. The trials above recorded absences of grade 3 or grade 4 hemorrhage and late unexpected effects. A phase I study was conducted by Seiwert et al (50), who demonstrated that the safe dose of bevacizumab is $10 \mathrm{mg} / \mathrm{kg}$ every 2 weeks when added to fluorouracil and hydroxyurea-based chemoradiotherapy.

Targeted therapy is a novel strategy that has achieved remarkable progress in recent years. Various targeted drugs have been found and tested in clinical trials. However, few of them have been approved by the US Food and Drug Administration, which required further randomized trials. Gene mutation of the tumor is also a key point for sensitivity of targeted therapy (56). In the future, molecular targeted drugs should be more specific and feature a narrow spectrum with minimal toxicity in clinical use for suitable patients after strict selection (57).

In conclusion, bevacizumab is effective and safe when added to RT and chemotherapy for patients with locally advanced and metastatic NPC. Several phase I II clinical trials have shown promising results in terms of local control and survival rates. However, phase III trials are insufficient to change the therapeutic principle, rendering an urgent need for additional in-depth studies. In the future, bevacizumab may be a potential molecular target drug for locally advanced and metastatic NPC.

\section{Acknowledgements}

Not applicable.

\section{Funding}

The present study was supported by the Science and Technology Innovation Fund of Guangdong Medical College, China (grant no. STIF201126) and Excellent Master's Thesis Fostering Fund of Affiliated Hospital of Guangdong Medical College, China (grant no. YS1108).

\section{Availability of data and materials}

All data generated or analyzed during this study are included in this published article.

\section{Authors' contributions}

QLL designed the study; XXP and SAC collected the patient data; GLY, LJ and HJZ read and analyzed the literature; HJZ wrote the manuscript; HJZ and QLL critically revised the manuscript. The final version of the manuscript was read and approved by all authors.

\section{Ethics approval and consent to participate}

The present study was has been approved by the Affiliated Hospital of Guangdong Medical University Ethics Committee (Zhanjiang, China), and informed consent was obtained from the participating patient.

\section{Consent for publication}

Written informed consent for the publication of the clinical details and images was obtained from the patient.

\section{Competing interests}

The authors declare that they have no competing interests.

\section{References}

1. Tan J, Jiang L, Cheng X, Wang C, Chen J, Huang X, Xie P, Xia D, Wang R and Zhang Y: Association between VEGF-460T/C gene polymorphism and clinical outcomes of nasopharyngeal carcinoma treated with intensity-modulated radiation therapy. Onco Targets Ther 10: 909-918, 2017.

2. Chen W and Hu GH: Biomarkers for enhancing the radiosensitivity of nasopharyngeal carcinoma. Cancer Biol Med 12: 23-32, 2015.

3. Chan AT, Teo PM and Johnson PJ: Nasopharyngeal carcinoma. Ann Oncol 12: 1007-1015, 2002.

4. Tulalamba W and Janvilisri T: Nasopharyngeal carcinoma signaling pathway: An update on molecular biomarkers. Int J Cell Biol 2012: 594681, 2012.

5. Wei WI and Kwong DL: Current management strategy of nasopharyngeal carcinoma. Clin Exp Otorhinolaryngol 3: 1-12, 2010.

6. Xue C, Tian Y, Zhang J, Zhao Y, Zhan J, Fang W and Zhang L: Efficacy of BIBF 1120 or BIBF 1120 plus chemotherapy on nasopharyngeal carcinoma in vitro and in vivo. Drug Des Devel Ther 10: 1173-1180, 2016.

7. Lee NY, Zhang Q, Pfister DG, Kim J, Garden AS, Mechalakos J, $\mathrm{Hu}$ K, Le QT, Colevas AD, Glisson BS, et al: Addition of bevacizumab to standard chemoradiation for locoregionally advanced nasopharyngeal carcinoma (RTOG 0615): A phase 2 multi-institutional trial. Lancet Oncol 13: 172-180, 2012.

8. Simo R, Robinson M, Lei M, Sibtain A and Hickey S: Nasopharyngeal carcinoma: United kingdom national multidisciplinary guidelines. J Laryngol Otol 130 (Suppl): S97-S103, 2016.

9. Xu T, Tang J, Gu M, Liu L, Wei W and Yang H: Recurrent nasopharyngeal carcinoma: A clinical dilemma and challenge. Curr Oncol 20: e406-e419, 2013.

10. Suárez C, Rodrigo JP, Rinaldo A, Langendijk JA, Shaha AR and Ferlito A: Current treatment options for recurrent nasopharyngeal cancer. Eur Arch Otorhinolaryngol 267: 1811-1824, 2010.

11. Lee V, Kwong D, Leung TW, Lam KO, Tong CC and Lee A: Palliative systemic therapy for recurrent or metastatic nasopharyngeal carcinoma-How far have we achieved? Crit Rev Oncol/Hematol 114: 13-23, 2017.

12. He W, Zou C, Tian Z, Tan W, Shen W, Chen J, Liu L and Xu R: Nasopharyngeal carcinoma treated with bevacizumab combined with paclitaxel liposome plus cisplatin: A case report and literature review. Onco Targets Ther 10: 67-72, 2016.

13. Carla C, Daris F, Cecilia B, Francesca B, Francesca C and Paolo F: Angiogenesis in head and neck cancer: A review of the literature. J Oncol 2012: 358472, 2012.

14. NCCN Clinical Practice Guidelines in Oncology: Head and neck cancers, 2017 version I.

15. Edge SB, Byrd DR and Compton CC: AJCC Cancer Staging Handbook from the AJCC Cancer Staging Manual. 7th edition. Springer, New York, NY, pp408-408, 2011.

16. Zhang L, Chen QY, Liu H, Tang LQ and Mai HQ: Emerging treatment options for nasopharyngeal carcinoma. Drug Des Devel Ther 7: 37-52, 2013.

17. Matta A and Ralhan R: Overview of current and future biologically based targeted therapies in head and neck squamous cell carcinoma. Head Neck Oncol 1: 6, 2009.

18. Sha D, He YJ, Wang WB and Han JQ: Anti-nasopharyngeal carcinoma effect in vivo and in vitro of Avastin and adenovirus-thymidine kinase suicide gene. Zhonghua Er Bi Yan Hou Tou Jing Wai Ke Za Zhi 42: 526-532, 2007 (In Chinese). 
19. Zhang C, Yang X, Zhang Q, Yang B, Xu L, Qin Q, Zhu H, Liu J, Cai J, Tao G, et al: Berberine radiosensitizes human nasopharyngeal carcinoma by suppressing hypoxia-inducible factor-1 $\alpha$ expression. Acta Otolaryngol 134: 185-192, 2014.

20. Zhou S, Gu L, He J, Zhang H and Zhou M: MDM2 regulates vascular endothelial growth factor mRNA stabilization in hypoxia. Mol Cell Biol 31: 4928-4937, 2011.

21. Stadler ME, Patel MR, Couch ME and Hayes DN: Molecular biology of head and neck cancer: Risks and pathways. Hematol Oncol Clin North Am 22: 1009-1124.vii, 2008

22. Shi D, Guo W, Chen W, Fu L, Wang J, Tian Y, Xiao X, Kang T, Huang W and Deng W: Nicotine promotes proliferation of human nasopharyngeal carcinoma cells by regulating $\alpha 7 \mathrm{AChR}, \mathrm{ERK}$, HIF-1 $\alpha$ and VEGF/PEDF signaling. PLoS One 7: e43898, 2012.

23. Falchook GS, Wheler JJ, Naing A, Jackson EF, Janku F, Hong D, Ng CS, Tannir NM, Lawhorn KN, Huang M, et al: Targeting hypoxia-inducible factor- $1 \alpha(\mathrm{HIF}-1 \alpha)$ in combination with antiangiogenic therapy: A phase I trial of bortezomib plus bevacizumab. Oncotarget 5: 10280-10292, 2014.

24. Wakisaka N, Wen QH, Yoshizaki T, Nishimura T, Furukawa M, Kawahara E and Nakanishi I: Association of vascular endothelial growth factor expression with angiogenesis and lymph node metastasis in nasopharyngeal carcinoma. Laryngoscope 109: 810-814, 1999.

25. Druzgal CH, Chen Z, Yeh NT, Thomas GR, Ondrey FG, Duffey DC, Vilela RJ, Ende K, McCullagh L, Rudy SF, et al: A pilot study of longitudinal serum cytokine and angiogenesis factor levels as markers of therapeutic response and survival in patients with head and neck squamous cell carcinoma. Head Neck 27: 771-784, 2005

26. Chen $\mathrm{Z}$ and $\mathrm{Xu} \mathrm{XH}$ : Combining antiangiogenic therapy and radiation in nasopharyngeal carcinoma. Saudi Med J 36: 659-664, 2015

27. Sun $\mathrm{R}$, Wang $X$ and $\mathrm{Li} X$ : Correlation analysis of nasopharyngeal carcinoma TNM staging with serum EA IgA and VCA IgA in EBV and VEGF-C and -D. Med Sci Monit 21: 2105-2109, 2015.

28. Tung YT, Huang PW, Chou YC, Lai CW, Wang HP, Ho HC, Yen CC, Tu CY, Tsai TC, Yeh DC, et al: Lung tumorigenesis induced by human vascular endothelial growth factor (hVEGF)-A165 overexpression in transgenic mice and amelioration of tumor formation by miR-16. Oncotarget 6: 10222-10238, 2015 .

29. Xie M, He G, Wang R, Shi S, Chen J, Ye Y, Xie L, Yi X and Tang A: Matrine-induced apoptosis of human nasopharyngeal carcinoma cells via in vitro vascular endothelial growth factor-A/extracellular signal-regulated kinase1/2 pathway inactivation. Horm Metab Res 46: 556-560, 2014

30. Toi M, Matsumoto T and Bando H: Vascular endothelial growth factor: Its prognostic, predictive, and therapeutic implications. Lancet Oncol 2: 667-673, 2001

31. Fujita K, Sano D, Kimura M, Yamashita Y, Kawakami M, Ishiguro Y, Nishimura G, Matsuda $\mathrm{H}$ and Tsukuda M: Anti-tumor effects of bevacizumab in combination with paclitaxel on head and neck squamous cell carcinoma. Oncol Rep 18: 47-51, 2007.

32. Vaklavas C, Lenihan D, Kurzrock R and Tsimberidou AM: Anti-vascular endothelial growth factor therapies and cardiovascular toxicity: What are the important clinical markers to target? Oncologist 15: 130-141, 2010

33. Li Y, Lu J, Zhou S, Wang W, Tan G, Zhang Z, Dong Z, Kang T and Tang F: Clusterin induced by N,N'-Dinitrosopiperazine is involved in nasopharyngeal carcinoma metastasis. Oncotarget 7 : 5548-5563, 2016

34. Chen HH, Weng BQ, Cheng KJ, Liu HY, Wang SQ and Lu YY: Effect of the vascular endothelial growth factor expression level on angiopoietin-2-mediated nasopharyngeal carcinoma growth. Vasc Cell 6: 4, 2014.

35. Grunstein J, Roberts WG, Mathieu-Costello O, Hanahan D and Johnson RS: Tumor-derived expression of vascular endothelial growth factor is a critical factor in tumor expansion and vascular function. Cancer Res 59: 1592-1598, 1999.

36. Li YH, Hu CF, Shao Q, Huang MY, Hou JH, Xie D, Zeng YX and Shao JY: Elevated expressions of survivin and VEGF protein are strong independent predictors of survival in advanced nasopharyngeal carcinoma. J Transl Med 6: 1, 2008.

37. Hui HP, Chan AT, Pezzella F, Turley H, To KF, Poon TC, Zee B, MoF,TeoPM,Huang DP, et al: Coexpression of Hypoxia-inducible factors 1alpha and 2alpha, carbonic anhydrase IX, and vascular endothelial growth factor in nasopharyngeal carcinoma and relationship to survival. Clin Cancer Res 8: 2595-2604, 2002.

38. Sung FL, Hui EP, Tao Q, Li H, Tsui NB, Lo YM, Ma BB, To KF, Harris AL and Chan AT: Genome-wide expression analysis using microarray identified complex signaling pathways modulated by hypoxia in nasopharyngeal carcinoma. Cancer Lett 253: 74-88, 2007.
39. Cohen EE, Davis DW, Karrison TG, Seiwert TY, Wong SJ, Nattam S, Kozloff MF, Clark JI, Yan DH, Liu W, et al: Erlotinib and bevacizumab in patients with recurrent or metastatic squamous cell carcinoma of the head and neck: A phase I/II study. Lancet Oncol 10: 247-257, 2009.

40. Yang L, Liu L, Xu Z, Liao W, Feng D, Dong X, Xu S, Xiao L, Lu J, Luo X, et al: EBV-LMP1 targeted DNAzyme enhances radiosensitivity by inhibiting tumor angiogenesis via the JNKs/HIF-1 pathway in nasopharyngeal carcinoma. Oncotarget 6: 5804-5817, 2015.

41. Qian CN, Zhang CQ, Guo X, Hong MH, Cao SM, Mai WY, Min HQ and Zeng YX: Elevation of serum vascular endothelial growth factor in male patients with metastatic nasopharyngeal carcinoma. Cancer 88: 255-261, 2000.

42. Le QT and Raben D: Integrating biologically targeted therapy in head and neck squamous cell carcinomas. Semin Radiat Oncol 19: 53-62, 2009.

43. Qian CN, Min HQ, Lin HL, Hong MH and Ye YL: Primary study in experimental antiangiogenic therapy of nasopharyngeal carcinoma with AGM-1470 (TNP-470). J Laryngol Otol 112: 849-853, 1998.

44. Wilken R, Veena MS, Wang MB and Srivatsan ES: Curcumin: A review of anti-cancer properties and therapeutic activity in head and neck squamous cell carcinoma. Mol Cancer 10: 12, 2011.

45. Specenier P and Vermorken JB: Biologic therapy in head and neck cancer: A road with hurdles. ISRN Oncol 2012: 163752, 2012.

46. Echarri MJ, Lopez-Martin A and Hitt R: Targeted therapy in locally advanced and Recurrent/metastatic head and neck squamous cell carcinoma (LA-R/M HNSCC). Cancers (Basel) 8: pii:E27, 2016.

47. Schmidt B, Lee HJ, Ryeom S and Yoon SS: Combining bevacizumab with radiation or chemoradiation for solid tumors: A review of the scientific rationale, and clinical trials. Curr Angiogenes 1: 169-179, 2012.

48. Li J, Zhao Z, Wu X, Yao J, Ma L, Ye R, Niu B, Liang L, Zhao X and Wang Q: Bevacizumab plus cisplatin and helical tomotherapy in treatment of locally advanced nasopharyngeal carcinoma. Onco Targets Ther 8: 1315-1319, 2015.

49. Spratt DE and Lee N: Current and emerging treatment options for nasopharyngeal carcinoma. Onco Targets Ther 5: 297-308, 2012.

50. Seiwert TY, Haraf DJ, Cohen EE, Stenson K, Witt ME, Dekker A, Kocherginsky M, Weichselbaum RR, Chen HX and Vokes EE: Phase I study of bevacizumab added to fluorouracil- and hydroxyurea-based concomitant chemoradiotherapy for poor-prognosis head and neck cancer. J Clin Oncol 26: 1732-1741, 2008.

51. Pfister DG, Lee NY, Sherman E, Lisa D, Carlson D, Stambuk H, Shen R, Kraus D, Shah J and Fury MG: Phase II study of bevacizumab (B) plus cisplatin (C) plus intensity-modulated radiation therapy (IMRT) for locoregionally advanced head and neck squamous cell cancer (HNSCC): Preliminary results. J Clin Oncol 27: 6013, 2009.

52. Fury MG, Lee NY, Sherman E, Lisa D, Kelly K, Lipson B, Carlson D, Stambuk H, Haque S, Shen R, et al: A phase 2 study of bevacizumab with cisplatin plus intensity-modulated radiation therapy for stage III/IVB head and neck squamous cell cancer. Cancer 118: 5008-5014, 2012.

53. Meluch AA, Spigel D, Burris HA, Lane C, Peyton JD, Shipley D, Rubin M, Stipanov M, Greco FA and Hainsworth JD: Combined modality therapy with radiation therapy (RT), chemotherapy, bevacizumab, and erlotinib in the treatment of patients (pts) with locally advanced squamous carcinoma of the head and neck. J Clin Oncol 27 (15 Suppl): 6012, 2009.

54. Lu J, Zhang K, Chen S and Wen W: Grape seed extract inhibits VEGF expression via reducing HIF-1alpha protein expression. Carcinogenesis 30: 636-644, 2009.

55. Hoffmann TK: Systemic therapy strategies for head-neck carcinomas: Current status. GMS Curr Top Otorhinolaryngol Head Neck Surg 11: Doc03, 2012.

56. Zhang JW, Qin T, Hong SD, Zhang J, Fang WF, Zhao YY, Yang YP, Xue C, Huang Y, Zhao HY, et al: Multiple oncogenic mutations related to targeted therapy in nasopharyngeal carcinoma. Chin J Cancer 34: 177-183, 2015.

57. Chan SL and Ma BB: Novel systemic therapeutic for nasopharyngeal carcinoma. Expert Opin Ther Targets 16 (Suppl 1): S63-S68, 2012.

This work is licensed under a Creative Commons Attribution-NonCommercial-NoDerivatives 4.0 International (CC BY-NC-ND 4.0) License. 